\title{
Synaptic Deficits Are Rescued in the p25/Cdk5 Model of Neurodegeneration by the Reduction of $\beta$-Secretase (BACE1)
}

\author{
Paola Giusti-Rodríguez, ${ }^{1,2}$ Jun Gao, ${ }^{1,2}$ Johannes Gräff, ${ }^{1,2}$ Damien Rei, ${ }^{1,2}$ Takahiro Soda, ${ }^{1,2}$ and Li-Huei Tsai ${ }^{1,2,3}$ \\ ${ }^{1}$ Department of Brain and Cognitive Sciences, Picower Institute for Learning and Memory, and ${ }^{2}$ Howard Hughes Medical Institute, Massachusetts Institute \\ of Technology, Cambridge, Massachusetts 02139, and 3Stanley Center for Psychiatric Research, Broad Institute, Cambridge, Massachusetts 02124
}

\begin{abstract}
Alzheimer's disease (AD) is the most common cause of dementia, and is characterized by memory loss and cognitive decline, as well as amyloid $\beta(\mathrm{A} \beta)$ accumulation, and progressive neurodegeneration. Cdk5 is a proline-directed serine/threonine kinase whose activation by the p 25 protein has been implicated in a number of neurodegenerative disorders. The CK-p25 inducible mouse model exhibits progressive neuronal death, elevated $\mathrm{A} \beta$, reduced synaptic plasticity, and impaired learning following p 25 overexpression in forebrain neurons. Levels of $\mathrm{A} \beta$, as well as the APP processing enzyme, $\beta$-secretase (BACE1), are also increased in CK-p25 mice. It is unknown what role increased $\mathrm{A} \beta$ plays in the cognitive and neurodegenerative phenotype of the CK-p 25 mouse. In the current work, we restored $A \beta$ levels in the CK-p25 mouse to those of wild-type mice via the partial genetic deletion of BACE1, allowing us to examine the A $\beta$ independent phenotype of this mouse model. We show that, in the CK-p25 mouse, normalization of A $\beta$ levels led to a rescue of synaptic and cognitive deficits. Conversely, neuronal loss was not ameliorated. Our findings indicate that increases in p $25 / \mathrm{Cdk} 5$ activity may mediate cognitive and synaptic impairment via an A $\beta$-dependent pathway in the CK-p25 mouse. These findings explore the impact of targeting $\mathrm{A} \beta$ production in a mouse model of neurodegeneration and cognitive impairment, and how this may translate into therapeutic approaches for sporadic $\mathrm{AD}$.
\end{abstract}

\section{Introduction}

Alzheimer's disease (AD) is the most common type of dementia, with an incidence that increases with age. The great majority of $\mathrm{AD}$ cases are sporadic and idiopathic. Amyloid plaques are a defining histological characteristic of AD (Hardy, 2006). Amyloid $\beta(\mathrm{A} \beta)$ peptides, which can exist as oligomers or aggregate into amyloid plaques, are generated upon the sequential cleavage of APP, which is initiated by the $\beta$-site amyloid precursor cleaving enzyme (BACE1) (Vassar et al., 1999).

Cyclin-dependent kinase $5(\mathrm{Cdk} 5)$ is a proline-directed serine/threonine kinase that binds to one of two activators, p35 or p39 (Ko et al., 2001). Cdk5 regulates a multiplicity of physiological events in the CNS, including neuronal migration, neurite development, synaptic plasticity, and cognition (Dhavan and Tsai, 2001; Fischer et al., 2002; Tomizawa et al., 2002; Cheung and Ip, 2007; Kim and Ryan, 2010). The proteolytic cleavage of p35 into p25 by calpain, a $\mathrm{Ca}^{2+}$-dependent protease, leads to the

Received July 13, 2011; revised Sept. 16, 2011; accepted Sept. 21, 2011

Author contributions: P.G.-R. and L.-H.T. designed research; P.G.-R., J. Gao, J. Gräff, D.R., and T.S. performed research; P.G.-R., J. Gao, J. Gräff, D.R., and T.S. analyzed data; P.G.-R. and L.-H.T. wrote the paper.

This work is partially supported by National Institutes of Health Grant NIH R01NS051874 and by National Research Service Award Predoctoral Fellowship F31GM80055-03 (P.G.-R.). P.G.-R. is a former Ph.D. student in the Division of Medical Sciences, T.S. is a student in the M.D.-Ph.D. program of the Harvard-MIT Division of Health Sciences and Technology, Harvard Medical School, Boston, MA. We thank Dr. Alison Mungenast for help with manuscript preparation and Dr. Lily Moy and Dr. Froylan Calderón de Anda for technical help.

J. Gao's current address: Model Animal Research Center, MOE Key Laboratory of Model Animal for Disease Study, Nanjing University, Nanjing 210061, China.

Correspondence should be addressed to Li-Huei Tsai, Massachusetts Institute of Technology, Building 46, Room 4235, 77 Massachusetts Avenue, Cambridge, MA 02139. E-mail: Ihtsai@mit.edu.

DOI:10.1523/JNEUROSCI.3588-11.2011

Copyright $\odot 2011$ the authors $\quad 0270-6474 / 11 / 3115751-06 \$ 15.00 / 0$ prolonged activation and altered subcellular localization of Cdk5 (Lee et al., 2000; O'Hare et al., 2005). The generation of p25 has been linked to neurotoxicity and several neurodegenerative disorders including AD, amyotrophic lateral sclerosis, Parkinson's disease, Neiman Pick's Type C disease, and ischemic brain injury (Patrick et al., 1999; Nguyen et al., 2001; Sawamura et al., 2001; Wang et al., 2003; Qu et al., 2007).

We created a transgenic mouse that overexpresses the p 25 protein under the control of an inducible, calcium/calmodulindependent protein kinase II $\alpha$ (CaMKII) promoter (CK-p25 mice) (Cruz et al., 2003). These mice recapitulate many hallmark features of $\mathrm{AD}$, including progressive neuronal loss, elevated $\mathrm{A} \beta$, tau pathology, cognitive dysfunction, and impaired synaptic plasticity (Cruz et al., 2003; Fischer et al., 2005). p25/Cdk5 has been shown to upregulate BACE1 expression and activity through a transcriptional mechanism (Wen et al., 2008), and the CK-p25 mice accordingly exhibit increased BACE1 levels and activity, accompanied by the intraneuronal accumulation of $A \beta$ (Cruz et al., 2006).

Mouse models of $\mathrm{AD}$ in which $\mathrm{A} \beta$ is elevated via mutations in $\mathrm{APP}$ or in $\mathrm{A} \beta$ processing express significant cognitive and synaptic deficits. However, unlike both $\mathrm{AD}$ patients and mice overexpressing p25, these models exhibit little or no neuronal loss. To specifically examine the role of $\mathrm{A} \beta$ elevation in the CK-p25 mouse model of neurodegeneration, we evaluated the impact of p25 overexpression on a background of normalized $A \beta$ levels in the CK-p 25 mouse. To achieve this, we targeted $\mathrm{A} \beta$ production by breeding CK-p25 mice to BACE1 knock-out mice, an approach which has led to the amelioration of pathology in several mouse models of familial AD (FAD) (Ohno et al., 2004, 2007; 
Laird et al., 2005). We found that the deletion of a single copy of BACE1 in the CK-p25/BACE $1^{+/-}$compound mice reduced $\mathrm{A} \beta$ to baseline levels, and rescued synapse density, synaptic plasticity, and memory impairments in the CK-p25 mice, but not neuronal loss. These findings indicate that increases in p25/Cdk5 activity may mediate AD-like pathology via parallel pathways in the CK-p25 mouse, one of which involves increases in $\mathrm{A} \beta$ generation, synaptic dysfunction and cognitive decline, and a parallel pathway that leads to neuronal death.

\section{Materials and Methods}

Mice. Single CaMKII-tTA or TetO-p25-GFP transgenic mice were crossed to BACE1 ${ }^{-1-}$ mice (Cai et al., 2001) obtained from The Jackson Laboratory, and the resulting generations were mated to obtain the genotypes of interest. At 2 months of age, CK-p25 mice were induced for 6 weeks to obtain forebrain-specific p25 expression (Cruz et al., 2003). Littermates and same-sex mice were used for comparison whenever possible. All transgenes were heterozygous. Upon brain dissection, one hemisphere was drop-fixed in $4 \%$ paraformaldehyde (PFA), and the other was flash-frozen in liquid nitrogen. Alternatively, mice were perfused with $4 \%$ PFA before dissection of the hemispheres.

Immunoblot analysis. Forebrain lysates from 6-week induced mice were prepared as described previously (Cruz et al., 2003). Proteins were subjected to SDS-PAGE and immunoblot analysis using the following antibodies (1:1000 unless noted): DC17 (Cdk5, Tsai laboratory, 1:50), p35 (Tsai laboratory), GAPDH (Santa Cruz Biotechnology), pT205 (Invitrogen), C-APP (Sigma), BACE1 (D10E5 clone; Cell Signaling Technology).

$A \beta$ ELISA. Forebrain tissue was homogenized in an ice-cold $4 \times$ volume of PBS supplemented with $1 \times$ protease inhibitors (Roche), AEBSF (4-(2-aminoethyl)benzenesulfonyl fluoride) (Pierce), and $8.2 \mathrm{M}$ guanidine $/ 82 \mathrm{~mm}$ Tris $\mathrm{HCl}, \mathrm{pH} 8.0$, to a final concentration of $5 \mathrm{M}$ guanidine. Samples were processed with the Mouse A $\beta 42$ ELISA kit according to manufacturer's instructions (Invitrogen).

Immunohistochemistry. Forty-micrometerthick sections were prepared from fixed brains. Floating sections were labeled using the following antibodies (1:500): 4G8 (Covance), NeuN (Millipore), GFP (Aves Labs), and synaptophysin (Sigma). To quantify neuronal density, five comparable sections spanning the hippocampus were immunolabeled, and the total number of NeuN-positive cells in hippocampal area CA1 across all sections was counted blindly. 4G8 pictures were taken from comparable sections containing CA1 at the same rostrocaudal level. 4G8 puncta were defined as intracellular aggregates of $>5$ contiguous pixels of matching maximum intensity. For synaptophysin quantification, the stratum radiatum of the hippocampus was imaged using a $63 \times$ oil objective and $4 \times$ optical zoom, and the number of puncta with a diameter of $\sim 0.4 \mu \mathrm{m}$ was counted. Comparable sections were stained with Cresyl Violet dye, and total cell numbers were counted

E

BACE1

p25-GFP



B

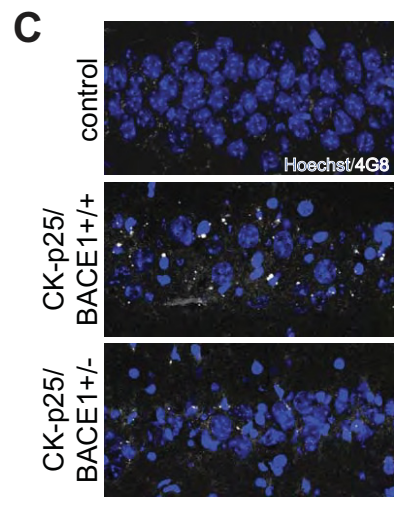

D
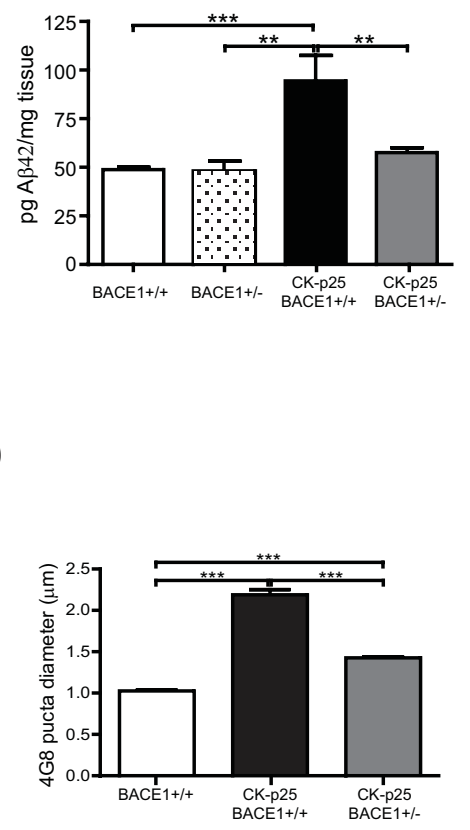

$\mathbf{F}$
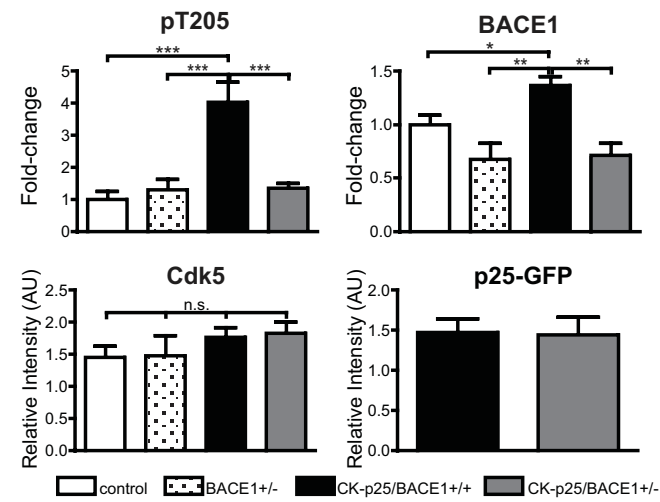

Figure 1. CK-p25/BACE1 ${ }^{+/-}$mice exhibit normalized $A \beta$ production and tau phosphorylation. $A$, Immunoblot analysis of forebrain lysates from 6-week induced CK-p25/BACE ${ }^{+/-}$brains revealed a significant decrease in the APP C-terminal fragments generated by BACE1 processing of APP when compared with CK-p25/BACE $1^{+/+}$mice $(n=5-6$ mice/genotype). $B$, Mouse $A \beta_{42}$ ELISA demonstrated significantly reduced $A \beta_{1-42}$ levels in CK-p25 mice hemizygous for BACE1 ( $n=$ 6-7 mice/genotype). $A \beta_{1-42}$ levels were indistinguishable between BACE1 ${ }^{+/+}$and BACE1 ${ }^{+/-}$mice. C, Representative images of $4 \mathrm{G} 8$ immunoreactivity in hippocampal area CA1. Scale bar, $10 \mu \mathrm{m} . \boldsymbol{D}, 4 \mathrm{G} 8$ punctum diameter is significantly decreased in CK-p25/BACE1 ${ }^{+/-}$mice compared with $\mathrm{CK}_{-\mathrm{p} 25 / \mathrm{BACE}^{+/+}}$mice $(n=3-4$ mice/genotype). E, CK-p25/ $\mathrm{BACE}^{+/-}$exhibited a decrease in phosphorylated Thr205 tau, when compared with $\mathrm{CK}-\mathrm{p} 25 / \mathrm{BACE} 1^{+/+}$mice. $F$, Densitometry analysis of phosphorylated tau at residue Thr205 relative to total protein (top left), and BACE1 protein levels (top right). Cdk5 levels are not significantly different between the four genotypes (bottom left). p25-GFP levels are not significantly different between the CK-p25/BACE1 ${ }^{+/+}$and CK-p25/BACE1 ${ }^{+/-}$mice (bottom right). Results are presented as fold-change over control or relative intensity ( $n=4-6$ mice/genotype). One-way ANOVA followed by Newman-Keuls post hoc test. Mean \pm SEM. ${ }^{*} p=<0.05,{ }^{* *} p=<0.01,{ }^{* * *} p=<0.001$.

under a light microscope. Immunofluorescent images were acquired using a Zeiss confocal microscope. All cell counts were quantified blindly.

Animal behavior. Context-dependent fear conditioning was performed as described previously (Guan et al., 2009). Briefly, mice were trained by exposure to the context, followed by a foot shock $(2 \mathrm{~s} ; 0.5,0.8$ $\mathrm{mA}$ constant current). Freezing behavior was recorded $24 \mathrm{~h}$ later upon reexposure of the mice to the conditioning context.

Electrophysiological analysis. Electrophysiological analysis was performed as described previously (Guan et al., 2009). Recordings were 
A



B
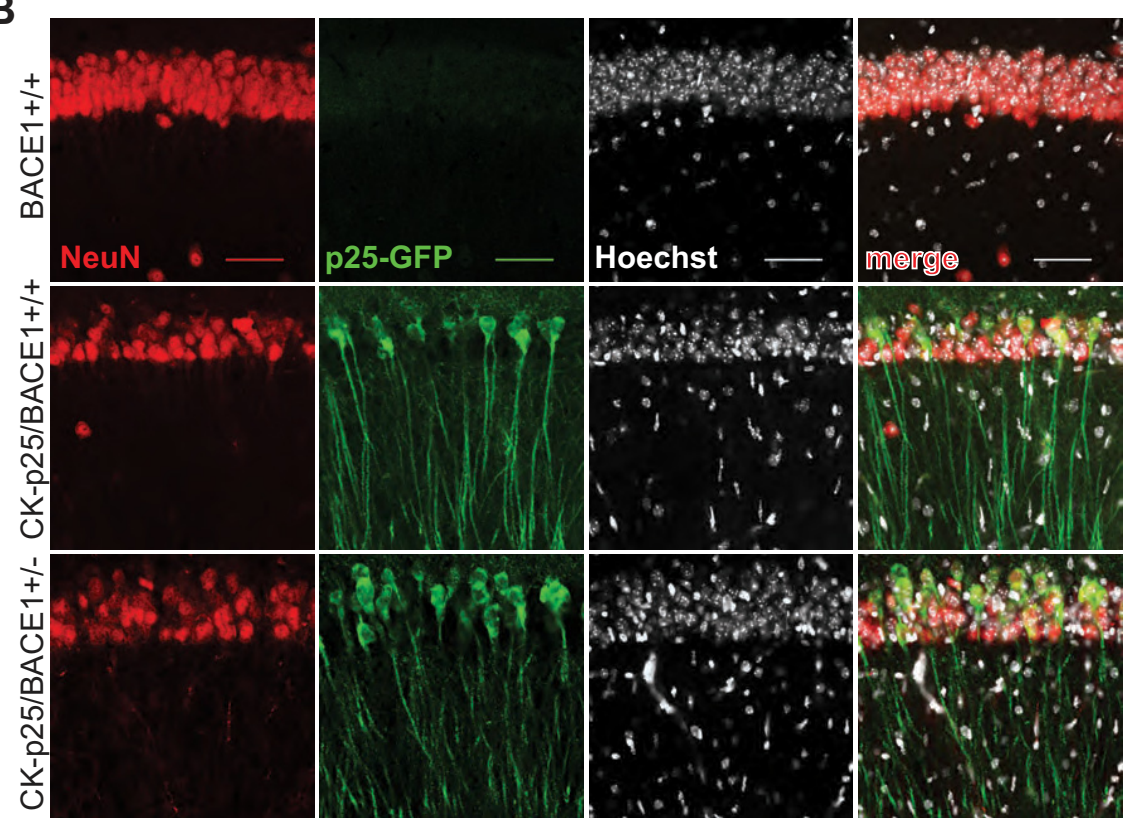

C

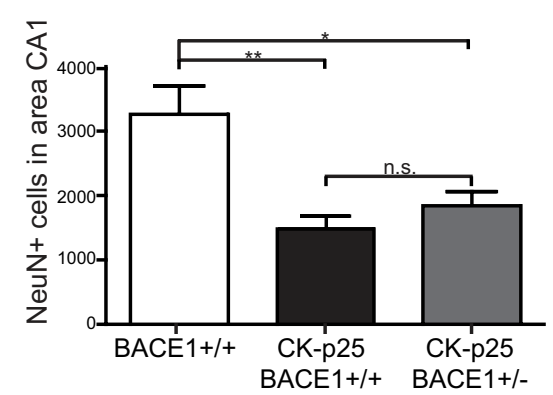

Figure 2. BACE1 hemizygosity does not rescue neuronal death in CK-p25 mice. A, BACE1 genotype does not affect the significant decrease in brain weight in CK-p25 mice. B, C, Severe neuronal death in hippocampal area CA1 is evident in CK-p25/ BACE1 ${ }^{+/-}$mice ( $n=3-6$ mice/genotype). Mean \pm SEM. One-way ANOVA with Tukey's multiple-comparison post hoc test. Scale bar, $25 \mu \mathrm{m} .{ }^{*} p=<0.05,{ }^{* *} p=<0.01$

made using transverse ( $400 \mu \mathrm{m})$ hippocampal slices prepared from 3to 4 -month-old mice. Baseline responses were recorded for $30 \mathrm{~min}$.

\section{Results}

CK-p25 mice hemizygous for BACE1 have decreased APP processing and reduced tau phosphorylation

We performed biochemical analyses of brain lysates from $\sim 3$ month-old CK-p25/BACE1 $1^{+/}$, CK-p25/BACE $1^{+/-}$mice and their control littermates, following 6 weeks of p25 induction. We show that the CK-p25/BACE1 ${ }^{+/-}$mice displayed lower levels of the BACE1-cleaved APP C-terminal fragment (C-APP) com- pared with CK-p25/BACE1 ${ }^{+/+}$mice (Fig. $1 A$ ), and were not significantly different from control levels. To confirm the reduction in APP processing, we performed an ELISA on forebrain tissue from 6-week induced CK-p25 mice. Importantly, $\mathrm{A} \beta_{1-42}$ levels in CK-p25 mice hemizygous for BACE1 were comparable to those of wildtype $\left(\mathrm{BACE}^{+/+}\right)$and $\mathrm{BACE} 1^{+/-}$mice (Fig. $1 B$ ), while significantly elevated in the CKp25/BACE ${ }^{+/+}$mice. Moreover, fluorescent immunolabeling of hippocampal sections with the anti- $\mathrm{A} \beta$ antibody $4 \mathrm{G} 8$ demonstrated a significant decrease in the diameter of intraneuronal 4G8immunoreactive puncta in area CA1 neurons, although the average diameter is still higher than that of the controls (Fig. 1C,D). We also confirmed that the CK-p25/BACE $1^{+/-}$mice exhibited reduced BACE1 levels compared with CKp25/BACE $1^{+/+}$mice, which were comparable to controls (Fig. 1E,F). Levels of Cdk 5 did not differ among the genotypes, nor did p25 levels differ between the CK-p25/BACE1 ${ }^{+/-}$and the CKp25/BACE1 ${ }^{+/+}$groups (Fig. 1E,F). We found that CK-p25 mice hemizygous for BACE1 (CK-p25/BACE1 ${ }^{+/-}$) exhibited normalized tau phosphorylation at several epitopes, including Thr205 (Fig. $1 E, F)$, and Ser202 (data not shown), while their CK-p25/BACE $1^{+/+}$littermates displayed the increased tau phosphorylation typical of the CK-p25 genotype. As described previously (Sankaranarayanan et al., 2008; Kim et al., 2011), BACE $1^{+/+}$and $\mathrm{BACE}^{+/-}$mice exhibited similar processing of BACE1 substrates such as $\mathrm{Na}_{\mathrm{v}} 1.1$ and neuregulin 1 (data not shown). These results validate the partial deletion of BACE1 as a means to normalize amyloidogenic APP processing in the CK-p25 mouse.

\section{Normalization of $A \beta$ level does not rescue neuronal loss in the CK-p25 mouse}

The expression of p25 leads to severe neuronal death and neurodegeneration in the CK-p25 mouse (Cruz et al., 2003). Accordingly, total brain weight was significantly reduced in 6-week-induced CKp25 mice compared with controls (Fig. $2 A$ ). Lowering $A \beta$ levels via BACE1 hemizygosity in the CK-p25 mice did not rescue the reduced brain weight in the CK-p25/ BACE $1^{+/-}$mice (Fig. $2 A$ ). We observed a nearly $50 \%$ reduction in the number of NeuN-positive cells in hippocampal area CA1 in the 6-week-induced CK-p25 mice, and this neuronal loss was not rescued in the CK-p25/BACE1 ${ }^{+/-}$mice (Fig. $2 B, C$ ). Additional analyses using FluoroJade staining confirmed that both CK-p25 groups showed significant neuronal death (data not shown). Furthermore, both CK-p25 genotypes presented significantly elevated levels of GFAP immunoreactivity in the cortex and 
hippocampus, indicative of reactive astrogliosis (data not shown). In a number of neuropathologies, including $\mathrm{AD}$, that involve neuronal loss, neurons engage in aberrant cell cycle behavior and show evidence of DNA damage (Butterfield et al., 2001; Lu et al., 2004; Herrup and Yang, 2007). Likewise, the CKp25 mouse exhibits ectopic neuronal cell-cycle protein expression and DNA double-strand breaks following 2 weeks of p25 induction (Kim et al., 2008). However, the normalization of $\mathrm{A} \beta$ levels in the CK-p25/BACE1 ${ }^{+/-}$does not ameliorate the DNA damage or cell-cycle reentry phenotype, as detectable by $\gamma \mathrm{H} 2 \mathrm{AX}$ and Ki67 immunoreactivity, respectively (data not shown). Together, these results suggest that non-amyloid mechanisms may underlie the severe neurodegeneration of the CK-p25 mouse.

\section{BACE1 hemizygosity rescues memory impairments in the} CK-p25 mice

The CK-p25 mice exhibit significant impairments in associative learning following prolonged expression of the p25 transgene (Fischer et al., 2005). To examine how the removal of elevated A $\beta$ levels impacts the associative learning deficits of the CK-p25 mice, we examined 6-week-induced animals using contextual fear conditioning, a hippocampus-dependent task. CK-p25/ BACE $1^{+/-}$mice froze significantly more than CK-p25/ BACE $1^{+/+}$mice, and were indistinguishable from controls (Fig. $3 A$ ). Both exploratory behavior and response to the foot shock did not differ between the different genotypes (Fig. $3 B, C$ ). Thus, normalizing $\mathrm{A} \beta$ levels ameliorates cognitive impairments in the CK-p25 mice.

The normalization of $A \beta$ levels via BACE1 hemizygosity restores synaptic plasticity and synapse density in the CK-p25 mouse hippocampus

We next examined long-term potentiation (LTP) in hippocampal area CA1 to determine how the normalization of $A \beta$ levels would impact the phenotype of impaired synaptic plasticity in the CK-p25 mice. Consistent with previous observations (Fischer et al., 2005), the CK-p25/BACE1 ${ }^{+/+}$mice displayed diminished CA1 LTP following a 6-week induction of p25 (red; Fig. 4A). Strikingly, LTP was fully restored to wild-type levels in the CKp25/BACE1 ${ }^{+/-}$mice (green; Fig. $4 A$ ). All groups of mice exhibited normal basal synaptic properties (Fig. $4 B$ ).

The pathology of Alzheimer's disease includes significant synaptic loss, which correlates with memory impairments (DeKosky and Scheff, 1990; Honer, 2003). The presynaptic protein synaptophysin has been widely used as a synaptic marker (Honer, 2003). We performed an analysis of synaptophysin-immunoreactive puncta (diameter $\sim 0.4 \mu \mathrm{m}$ ) in neurons from 6-week induced CK-p25 mice and their control littermates. Consistent with previous reports in the CK-p25 mouse (Fischer et al., 2007), CK-p25/BACE1 ${ }^{+/+}$mice exhibited a significantly reduced density of synaptophysin puncta in the stratum radiatum of the hippocampus (Fig. 4C,D). The normalization of $\mathrm{A} \beta$ levels in the $\mathrm{CK}-\mathrm{p} 25 / \mathrm{BACE} 1^{+/-}$mice led to a striking recovery in the density of synaptophysin-immunoreactive puncta, to levels that were not statistically different from those of the BACE $1^{+/+}$and BACE1 ${ }^{+/-}$mice. Together, the results of the current work demonstrate that the normalization of $\mathrm{A} \beta$ concentration in the brains of CK-p25 mice rescues the synaptic and cognitive impairments associated with p25 overexpression, but that p25dependent neuronal loss occurs via a mechanism independent of $\mathrm{A} \beta$ generation.

\section{Discussion}

The goal of the current work is to delineate the role of elevated $\mathrm{A} \beta$ in the CK-p25 phenotype of AD-like neurodegeneration and cog-
A

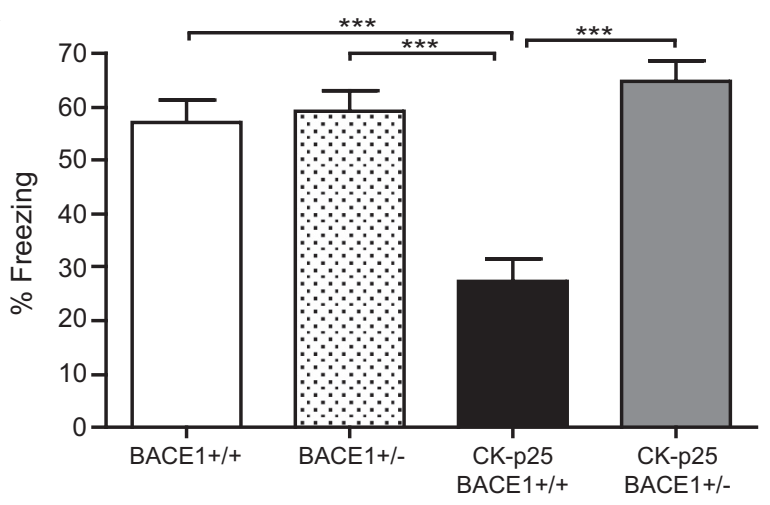

B
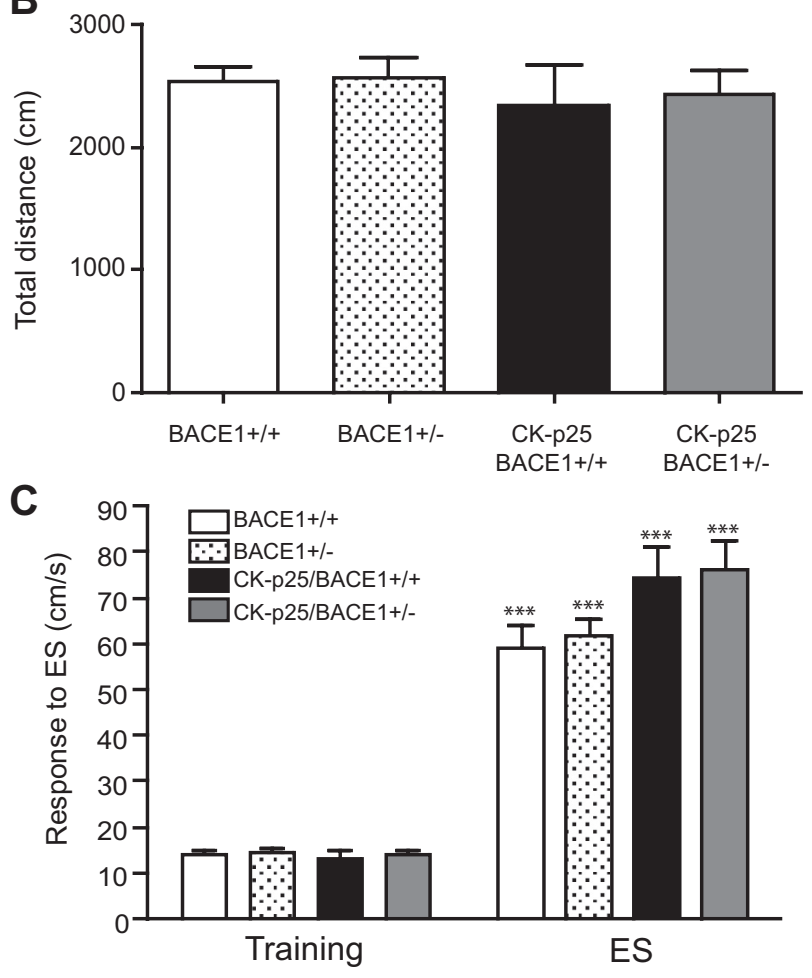

Figure 3. $\quad$ CK-p25/BACE1 ${ }^{+/}$mice exhibit normal associative learning. $\boldsymbol{A}$, Percentage of time spent freezing exhibited by CK-p25 mice $24 \mathrm{~h}$ after training in context-dependent fear conditioning. $\boldsymbol{B}, \boldsymbol{C}$, No differences were observed in the exploratory behavior of the mice $(\boldsymbol{B})$ or in their response to the foot shock (C). One-way ANOVA and Tukey's multiple-comparisons post hoc test. $n=9-12$ mice/genotype. ${ }^{* * *} p=<0.001$.

nitive impairment. In human $\mathrm{AD}$ patients, neuropathology is characterized by both neuronal and synaptic loss (Davies et al., 1987; Selkoe, 2002). In mouse models of AD in which amyloid processing is affected, there is a noteworthy lack of significant neurodegeneration despite heavy $\mathrm{A} \beta$ burdens and profound cognitive decline (for review, see Chin, 2011). However, the CK-p25 mouse also displays severe neurodegeneration, including extensive neuronal death, even though the increase in endogenous $\mathrm{A} \beta$ in these mice is relatively modest (Cruz et al., 2006).

Reductions in $\mathrm{A} \beta$ generation effected by deletion of BACE1 have been shown to ameliorate the phenotypes of mouse AD models such as the Tg2576 (Ohno et al., 2004), 5XFAD (Ohno et al., 2007), and APPswe;PS1 $\Delta$ E9 lines (Laird et al., 2005). We used a similar approach to examine the contribution of elevated $\mathrm{A} \beta$ levels to p25-induced neurodegeneration. In our approach, $\mathrm{BACE} 1$ activity and $\mathrm{A} \beta$ generation in CK-p25 mice was normal- 
A

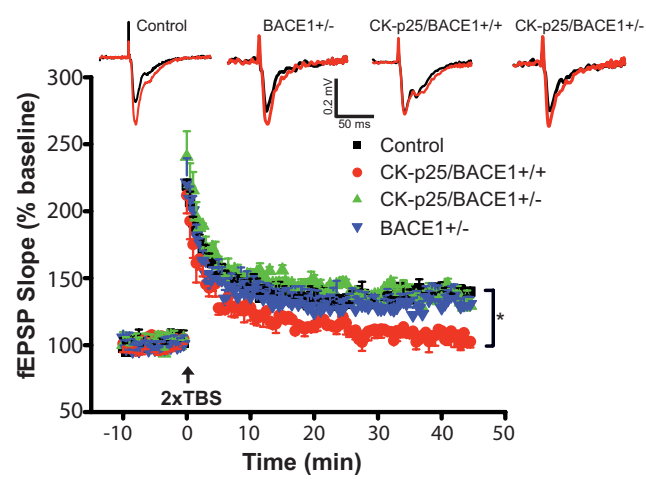

B
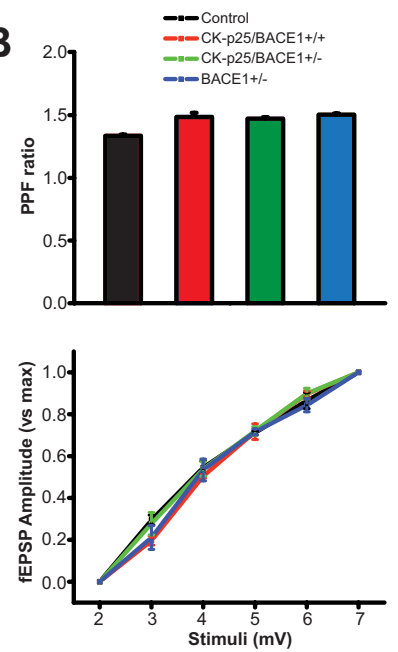

C


D

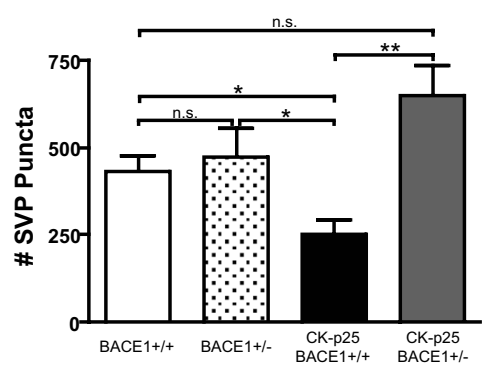

part by reduced synaptic density (DeKosky and Scheff, 1990). The expression ( $\geq$ 6-weeks) of the p 25 transgene gives rise to similar phenotypes, with mice exhibiting decreases in synaptophysin immunoreactivity, learning and memory, and synaptic plasticity. The restoration of cognitive function and synaptic plasticity that we observe in CK-p25 mice upon $\mathrm{A} \beta$ normalization, in the absence of protection against neuronal death, argues for a separation in the etiology of these pathologies in this mouse model, such that p25/Cdk5induced increases in $\mathrm{A} \beta$ generation may be responsible for synaptic dysfunction, while other mechanisms underlie neuronal death. This concept is supported by the recent findings of a specific role for $A \beta$ in synaptic dysfunction in the absence of neuronal loss (Cissé et al., 2011; D’Amelio et al., 2011). The apparent disconnect between functional recovery and neuronal death is striking, but not unprecedented (Pesavento et al., 2002; Nahm et al., 2003; Fischer et al., 2007) and suggests that, in the course of neurodegeneration, the function of remaining neurons may be improved via various interventions, even though the disease itself may not be slowed or halted.

Neuronal death observed in the CK-p25 mice may be explained by the phenomena of genomic instability and ectopic cell-cycle protein expression that are observed before neuronal death, and which are mediated by the inhibition of the histone deacetylase 1 (HDAC1) protein (Kim et al., 2008). In addition, other groups have described a neurotoxic role for $\mathrm{p} 25 / \mathrm{Cdk} 5$ in the nucleus, where its ac-

Figure 4. Synaptic plasticity and density are restored in CK-p25/BACE1 ${ }^{+/-}$mice. A, LTP elicited by $2 \times$ TBS was measured in area CA1 of the hippocampus. CK-p25/BACE1 ${ }^{+/-}$and control mice were indistinguishable in their LTP measurements, which were significantly higher than the CK-p25/BACE1 ${ }^{+/+}$mice. B, Paired-pulse facilitation (top) and field EPSP amplitude (bottom) did not differ between the four groups of mice $(n=4$ mice/group). Error bar $=$ SEM. C, Representative images of synaptophysin (SVP) immunoreactivity in stratum radiatum of the hippocampus of 6-week induced CK-p25 mice and controls. D, Quantification of SVP puncta demonstrates a significant rescue of synaptic density in the CK-p25/BACE1 ${ }^{+/-}$mice $(n=3-5$ mice/genotype) Scale bar, $5 \mu \mathrm{m} .{ }^{*} p=<0.05,{ }^{* *} p=<0.01$.

ized via the deletion of one allele of the BACE1 enzyme, and mice were then examined for the occurrence of tau phosphorylation, neuron and synaptic loss, and cognitive dysfunction. While A $\beta 1-42$ levels do not appear to differ between wild-type and BACE1 ${ }^{+/-}$mice in our study, we have previously shown that BACE1 protein levels are increased in the CK-p25 mouse, which is accompanied by increased $A \beta$ production (Cruz et al., 2006). It was subsequently shown that $\mathrm{p} 25 / \mathrm{Cdk} 5$ upregulates the transcription of BACE1 (Wen et al., 2008). This is likely to be the main mechanism whereby the loss of one allele of BACE1 is able to reduce $\mathrm{A} \beta$ levels in CK-p 25 mice. Thus, BACE1 heterozygosity appears to be sufficient to normalize the increased $A \beta$ levels that result from BACE1 upregulation in the CK-p25 mouse. Although BACE1 homozygous knock-out animals have abnormalities in behavior, electrophysiology, myelination, and spine density, BACE1 heterozygotes appear to be normal in these measures (Laird et al., 2005; Savonenko et al., 2008). We found that CKp25 mice exhibiting wild-type levels of APP processing and A $\beta$ were protected from many $\mathrm{p} 25$-dependent pathologies, and had normal cognitive function, but still showed the extensive neuronal death typical of the CK-p25 phenotype.

Symptoms of cognitive impairments and changes in affect observed in $\mathrm{AD}$ may be due to synaptic dysfunction, reflected in tions may trigger aberrant cell-cycle reentry (O'Hare et al., 2005; Saito et al., 2007) as well as induce the phosphorylation and degradation of the transcription factor MEF2 following neurotoxicity, leading to cell death (Gong et al., 2003; Tang et al., 2005). $\mathrm{Cdk} 5$, in association with $\mathrm{p} 35$, has also been shown to be protective in the neuronal nucleus, where it suppresses cell cycle activity in the differentiated neuron (Cicero and Herrup, 2005; Zhang et al., 2010). Together, these observations suggest a model in which $\mathrm{A} \beta$ production facilitate synapse loss, and learning and synaptic deficits in the CK-p25 mouse, while neuronal death occurs via mechanisms less directly linked to amyloid. As $\mathrm{A} \beta$ also increases p25 production in neurons (Lee et al., 2000), these two pathways are intricately linked in a feedforward mechanism of p25 overproduction that likely culminates in both the cognitive deficits and neurodegeneration observed in the CK-p25 mouse and, potentially, in human $\mathrm{AD}$. Therefore, the inhibition of the p25/Cdk5 complex, while leaving the $\mathrm{p} 35 / \mathrm{Cdk} 5$ complex intact, is a promising avenue for the therapeutic intervention of neurodegenerative disease.

\section{References}

Butterfield DA, Drake J, Pocernich C, Castegna A (2001) Evidence of oxidative damage in Alzheimer's disease brain: central role for amyloid [beta]peptide. Trends Mol Med 7:548-554. 
Cai H, Wang Y, McCarthy D, Wen H, Borchelt DR, Price DL, Wong PC (2001) BACE1 is the major $\beta$-secretase for generation of $A \beta$ peptides by neurons. Nat Neurosci 4:233-234.

Cheung ZH, Ip NY (2007) The roles of cyclin-dependent kinase 5 in dendrite and synapse development. Biotechnol J 2:949-957.

Chin J (2011) Selecting a mouse model of Alzheimer's disease. Methods Mol Biol 670:169-189.

Cicero S, Herrup K (2005) Cyclin-dependent kinase 5 is essential for neuronal cell cycle arrest and differentiation. J Neurosci 25:9658-9668.

Cissé M, Halabisky B, Harris J, Devidze N, Dubal DB, Sun B, Orr A, Lotz G, Kim DH, Hamto P, Ho K, Yu GQ, Mucke L (2011) Reversing EphB2 depletion rescues cognitive functions in Alzheimer model. Nature 469:47-52.

Cruz JC, Tseng HC, Goldman JA, Shih H, Tsai LH (2003) Aberrant Cdk5 activation by $\mathrm{p} 25$ triggers pathological events leading to neurodegeneration and neurofibrillary tangles. Neuron 40:471-483.

Cruz JC, Kim D, Moy LY, Dobbin MM, Sun X, Bronson RT, Tsai LH (2006) p25/cyclin-dependent kinase 5 induces production and intraneuronal accumulation of amyloid beta in vivo. J Neurosci 26:10536-10541.

D'Amelio M, Cavallucci V, Middei S, Marchetti C, Pacioni S, Ferri A, Diamantini A, De Zio D, Carrara P, Battistini L, Moreno S, Bacci A, Ammassari-Teule M, Marie H, Cecconi F (2011) Caspase-3 triggers early synaptic dysfunction in a mouse model of Alzheimer's disease. Nat Neurosci 14:69-76.

Davies CA, Mann DM, Sumpter PQ, Yates PO (1987) A quantitative morphometric analysis of the neuronal and synaptic content of the frontal and temporal cortex in patients with Alzheimer's disease. J Neurol Sci 78:151-164.

DeKosky ST, Scheff SW (1990) Synapse loss in frontal cortex biopsies in Alzheimer's disease: correlation with cognitive severity. Ann Neurol 27:457-464.

Dhavan R, Tsai LH (2001) A decade of CDK5. Nat Rev Mol Cell Biol 2:749-759.

Fischer A, Sananbenesi F, Schrick C, Spiess J, Radulovic J (2002) Cyclindependent kinase 5 is required for associative learning. J Neurosci 22:3700-3707.

Fischer A, Sananbenesi F, Pang PT, Lu B, Tsai LH (2005) Opposing roles of transient and prolonged expression of p25 in synaptic plasticity and hippocampus-dependent memory. Neuron 48:825-838.

Fischer A, Sananbenesi F, Wang X, Dobbin M, Tsai LH (2007) Recovery of learning and memory is associated with chromatin remodelling. Nature 447:178-182.

Gong X, Tang X, Wiedmann M, Wang X, Peng J, Zheng D, Blair LA, Marshall J, Mao Z (2003) Cdk5-mediated inhibition of the protective effects of transcription factor MEF2 in neurotoxicity-induced apoptosis. Neuron 38:33-46.

Guan JS, Haggarty SJ, Giacometti E, Dannenberg JH, Joseph N, Gao J, Nieland TJ, Zhou Y, Wang X, Mazitschek R, Bradner JE, DePinho RA, Jaenisch R, Tsai LH (2009) HDAC2 negatively regulates memory formation and synaptic plasticity. Nature 459:55-60.

Hardy J (2006) A hundred years of Alzheimer's disease research. Neuron 52:3-13.

Herrup K, Yang Y (2007) Cell cycle regulation in the postmitotic neuron: oxymoron or new biology? Nat Rev Neurosci 8:368-378.

Honer WG (2003) Pathology of presynaptic proteins in Alzheimer's disease: more than simple loss of terminals. Neurobiol Aging 24:1047-1062.

Kim DY, Gersbacher MT, Inquimbert P, Kovacs DM (2011) Reduced sodium channel $\mathrm{Na}(\mathrm{v}) 1.1$ levels in BACE1-null mice. J Biol Chem 286:8106-8116.

Kim D, Frank CL, Dobbin MM, Tsunemoto RK, Tu W, Peng PL, Guan JS, Lee BH, Moy LY, Giusti P, Broodie N, Mazitschek R, Delalle I, Haggarty SJ, Neve RL, Lu Y, Tsai LH (2008) Deregulation of HDAC1 by p25/Cdk5 in neurotoxicity. Neuron 60:803-817.

Kim SH, Ryan TA (2010) CDK5 serves as a major control point in neurotransmitter release. Neuron 67:797-809.

Ko J, Humbert S, Bronson RT, Takahashi S, Kulkarni AB, Li E, Tsai LH (2001) p35 and p39 are essential for cyclin-dependent kinase 5 function during neurodevelopment. J Neurosci 21:6758-6771.

Laird FM, Cai H, Savonenko AV, Farah MH, He K, Melnikova T, Wen H, Chiang HC, Xu G, Koliatsos VE, Borchelt DR, Price DL, Lee HK, Wong PC (2005) BACE1, a major determinant of selective vulnerability of the brain to amyloid- $\beta$ amyloidogenesis, is essential for cognitive, emotional, and synaptic functions. J Neurosci 25:11693-11709.

Lee MS, Kwon YT, Li M, Peng J, Friedlander RM, Tsai LH (2000) Neurotoxicity induces cleavage of p35 to p25 by calpain. Nature 405:360-364.
Lu T, Pan Y, Kao SY, Li C, Kohane I, Chan J, Yankner BA (2004) Gene regulation and DNA damage in the ageing human brain. Nature 429:883-891.

Nahm SS, Frank TC, Browning MD, Sepulvado JM, Hiney JK, Abbott LC (2003) Insulin-like growth factor-I improves cerebellar dysfunction but does not prevent cerebellar neurodegeneration in the calcium channel mutant mouse, leaner. Neurobiol Dis 14:157-165.

Nguyen MD, Larivière RC, Julien JP (2001) Deregulation of Cdk5 in a mouse model of ALS: Toxicity alleviated by perikaryal neurofilament inclusions. Neuron 30:135-147.

O'Hare MJ, Kushwaha N, Zhang Y, Aleyasin H, Callaghan SM, Slack RS, Albert PR, Vincent I, Park DS (2005) Differential roles of nuclear and cytoplasmic cyclin-dependent kinase 5 in apoptotic and excitotoxic neuronal death. J Neurosci 25:8954-8966.

Ohno M, Sametsky EA, Younkin LH, Oakley H, Younkin SG, Citron M, Vassar R, Disterhoft JF (2004) BACE1 deficiency rescues memory deficits and cholinergic dysfunction in a mouse model of Alzheimer's disease. Neuron 41:27-33.

Ohno M, Cole SL, Yasvoina M, Zhao J, Citron M, Berry R, Disterhoft JF, Vassar R (2007) BACE1 gene deletion prevents neuron loss and memory deficits in 5XFAD APP/PS1 transgenic mice. Neurobiol Dis 26:134-145.

Patrick GN, Zukerberg L, Nikolic M, de la Monte S, Dikkes P, Tsai LH (1999) Conversion of p 35 to p 25 deregulates Cdk5 activity and promotes neurodegeneration. Nature 402:615-622.

Pesavento E, Capsoni S, Domenici L, Cattaneo A (2002) Acute cholinergic rescue of synaptic plasticity in the neurodegenerating cortex of antinerve-growth-factor mice. Eur J Neurosci 15:1030-1036.

Qu D, Rashidian J, Mount MP, Aleyasin H, Parsanejad M, Lira A, Haque E, Zhang Y, Callaghan S, Daigle M, Rousseaux MW, Slack RS, Albert PR, Vincent I, Woulfe JM, Park DS (2007) Role ofCdk5-mediated phosphorylation of Prx2 in MPTP toxicity and Parkinson's disease. Neuron 55:37-52.

Saito T, Konno T, Hosokawa T, Asada A, Ishiguro K, Hisanaga SI (2007) p25/ cyclin-dependent kinase 5 promotes the progression of cell death in nucleus of endoplasmic reticulum-stressed neurons. J Neurochem 102:133-140.

Sankaranarayanan S, Price EA, Wu G, Crouthamel MC, Shi XP, Tugusheva K, Tyler KX, Kahana J, Ellis J, Jin L, Steele T, Stachel S, Coburn C, Simon AJ (2008) In vivo beta-secretase 1 inhibition leads to brain Abeta lowering and increased alpha-secretase processing of amyloid precursor protein without effect on neuregulin-1. J Pharmacol Exp Ther 324:957-969.

Savonenko AV, Melnikova T, Laird FM, Stewart KA, Price DL, Wong PC (2008) Alteration of BACE1-dependent NRG1/ErbB4 signaling and schizophrenia-like phenotypes in BACE1-null mice. Proc Natl Acad Sci U S A 105:5585-5590.

Sawamura N, Gong JS, Garver WS, Heidenreich RA, Ninomiya H, Ohno K, Yanagisawa K, Michikawa M (2001) Site-specific phosphorylation of tau accompanied by activation of mitogen-activated protein kinase (MAPK) in brains of Niemann-Pick type C mice. J Biol Chem 276:10314-10319.

Selkoe DJ (2002) Alzheimer's disease is a synaptic failure. Science 298:789-791.

Tang X, Wang X, Gong X, Tong M, Park D, Xia Z, Mao Z (2005) Cyclindependent kinase 5 mediates neurotoxin-induced degradation of the transcription factor myocyte enhancer factor 2. J Neurosci 25:4823-4834.

Tomizawa K, Ohta J, Matsushita M, Moriwaki A, Li ST, Takei K, Matsui H (2002) Cdk5/p35 regulates neurotransmitter release through phosphorylation and downregulation of $\mathrm{P} / \mathrm{Q}$-type voltage-dependent calcium channel activity. J Neurosci 22:2590-2597.

Vassar R, Bennett BD, Babu-Khan S, Kahn S, Mendiaz EA, Denis P, Teplow DB, Ross S, Amarante P, Loeloff R, Luo Y, Fisher S, Fuller J, Edenson S, Lile J, Jarosinski MA, Biere AL, Curran E, Burgess T, Louis JC, et al. (1999) $\beta$-Secretase cleavage of Alzheimer's amyloid precursor protein by the transmembrane aspartic protease BACE. Science 286:735-741.

Wang J, Liu S, Fu Y, Wang JH, Lu Y (2003) Cdk5 activation induces hippocampal CA1 cell death by directly phosphorylating NMDA receptors. Nat Neurosci 6:1039-1047.

Wen Y, Yu WH, Maloney B, Bailey J, Ma J, Marié I, Maurin T, Wang L, Figueroa H, Herman M, Krishnamurthy P, Liu L, Planel E, Lau LF, Lahiri DK, Duff K (2008) Transcriptional regulation of [beta]-secretase by p25/cdk5 leads to enhanced amyloidogenic processing. Neuron 57:680-690.

Zhang J, Li H, Yabut O, Fitzpatrick H, D’Arcangelo G, Herrup K (2010) Cdk5 suppresses the neuronal cell cycle by disrupting the E2F1-DP1 complex. J Neurosci 30:5219-5228. 